\title{
Behaviour of single-sided composite joints at room temperature and in case of fire after an earthquake
}

\author{
Demonceau J.-F. ${ }^{1}$, Hanus F. ${ }^{1}$, Jaspart J.-P. ${ }^{1}$ \& Franssen J.-M. ${ }^{1}$ \\ ${ }^{1}$ University of Liège, Department ArGEnCo, Chemin des Chevreuils, 1 B52/3 4000 Liège, Belgium
}

\begin{abstract}
In 2003, a European research program entitled "PRECIOUS - Prefabricated composite beam-to-concrete filled tube or partially reinforced-concrete-encased column connections for severe seismic and fire loadings" and funded by the Research Fund for Coal and Steel (RFCS) was initiated for three years (Bursi et al, 2008). The objective of this project was to develop fundamental data, design guidelines and prequalification tools for two types of composite beam-to-column joints able to ensure a suitable behaviour during an earthquake and its eventual subsequent fire.

At the University of Liege, as part of this project, analytical and numerical investigations were conducted mainly on single-sided beam-to-column composite joints at room and at elevated temperatures. The present paper summarizes the activities developed within this project and presents the main achievements.
\end{abstract}

\section{Introduction}

The occurrence of a fire after an earthquake is a very severe scenario which was often observed in case of strong earthquakes (Lisbon earthquake in 1755, San Francisco earthquake in 1906, Tokyo earthquake in 1923, ...); generally, these subsequent fires are more destructive than the earthquake itself. Nowadays, the development of fires after an earthquake is mostly associated to the break of gas pipe or to electrical short-circuits.

In 2003, a European research program entitled "PRECIOUS - Prefabricated composite beam-to-concrete filled tube or partially reinforced-concrete-encased column connections for severe seismic and fire loadings” and funded by the Research Fund for Coal and Steel (RFCS) was initiated for three years (Bursi et al, 2008). The objective of this project was to develop fundamental data, design guidelines and prequalification tools for two types of composite beam-to-column joints able to ensure a suitable behaviour during an earthquake and its eventual subsequent fire. The two composite joint configurations which were investigated are: beam-to-partially reinforced-concrete-encased column joints with a bolted end-plate and I sections for the columns and the beams (called Type 1 joints) and beam-to-concrete filled tubular column joints with circular hollow sections for the columns and I sections for the beams (called Type 2 joints). 
Within this project, analytical, numerical and experimental activities were conducted. At the University of Liege, as part of this project, analytical and numerical investigations were mainly conducted on Type 1 joints. The developments introduced within the present paper are relative to recent investigations conducted on single-sided beam-to-column composite joints with a "Type 1" configuration. The paper will be divided in two main parts:

- A first part will be dedicated to the investigations conducted on these joints at room temperature. In particular, a new collapse mode identified through experimental tests will be described and a new analytical method to predict this collapse mode will be presented.

- Then, based on the knowledge gained from the previous part, the second part will present the investigations conducted on these joints subjected to a fire. In particular, simplified analytical models to predict the distribution of temperatures within the different part of the joints and to characterise their mechanical properties during a fire will be detailed.

\section{Behaviour of composite beam-to-partially encased column joints at room temperature}

The behaviour of composite beam-to-column joints subjected to hogging bending moments at room temperature is well known. Indeed, several experimental tests have been performed in the past and an analytical procedure founded on the general concept called "the component method" is now proposed in the Eurocodes ((Eurocode 31-8, 2005) and (Eurocode 4-1-1, 2004)) to characterise composite joints subjected to such a loading. However, through recent tests performed at the University of Liege on single-sided composite joints, a new collapse mode not covered by the Eurocode design recommendations was identified. Accordingly, an analytical method to predict this new collapse mode was developed and validated through comparisons to experimental test results (Demonceau, 2008). The present section reflects these developments. Section 2.1 first presents experimental tests performed on single-sided composite joints within two recent European RFCS projects and section 2.2 then details the developed analytical method to predict the identified new collapse mode.

\subsection{Description of recent experimental tests}

\subsubsection{Experimental tests performed at the University of Liege}

The experimental tests presented herein were realised in the framework of a European project entitled “Applicability of composite structures to sway frames” (Bitar et al, 2006). Cyclic and static tests on isolated joints were performed in different European laboratories to get the actual behaviour of the constitutive joints of two structures tested respectively at the JRC laboratory of Ispra and at the University of Bochum. As part of this project, the University of Liege performed two tests on isolated single-sided composite joints: one monotonic 
test (application of a hogging moment) and one cyclic test. Within the present paper, only the monotonic test will be considered.

Fig. 1 presents the configuration of the tested partial-strength single-sided composite joint; this joint was designed in order to obtain a ductile collapse mode and to develop a rotation capacity of at least 35 mRad so as to ensure an adequate behaviour of the joint in case of earthquake. The beam is made of an IPE300 section, and the column is made of a HEB260 section (partially encased). The composite slab has a total thickness of $150 \mathrm{~mm}$ and the corrugated steel sheet is an EGB 210 profile from BROLLO (Italy), with ribs perpendicular to the beam axis. The composite slab is connected to the upper beam flange by means of shear studs (full connection). The layout of the rebars in the slab is given in Fig. 2. The anti cracking mesh is made of rebars with a diameter of 6 $\mathrm{mm}$ and a spacing of $150 \mathrm{~mm}$ in each direction. The column is surrounded by two $12 \mathrm{~mm}$ rebars. The transversal reinforcement is made of $12 \mathrm{~mm}$ rebars, with additional bars placed close to the column. S235 steel grade was ordered for the beams, the columns and the beam end-plates; rebars are made of S500C steel. C25/30 concrete is
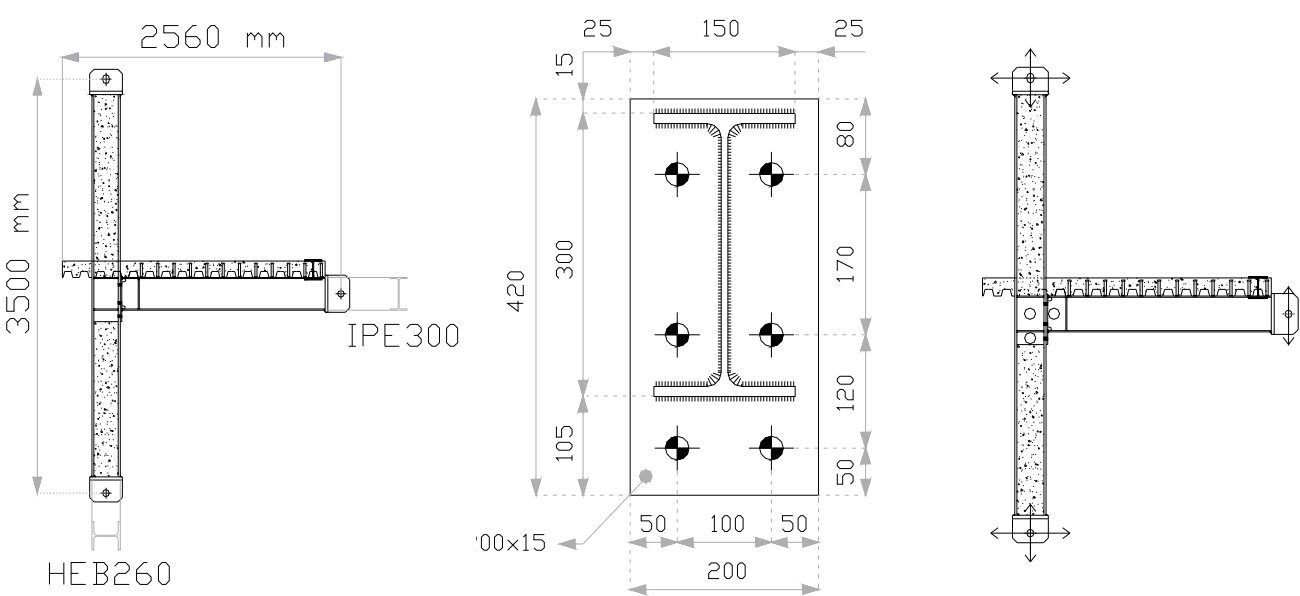

used for the slabs and the composite columns. The bolts are M24 grade 10.9; they are preloaded at 75\% with an additional rotation of $60^{\circ}$. More details about these specimens are given in (Demonceau et al, 2003).

Figure 1. Properties (in mm) and instrumentation of the single-sided composite joint specimen

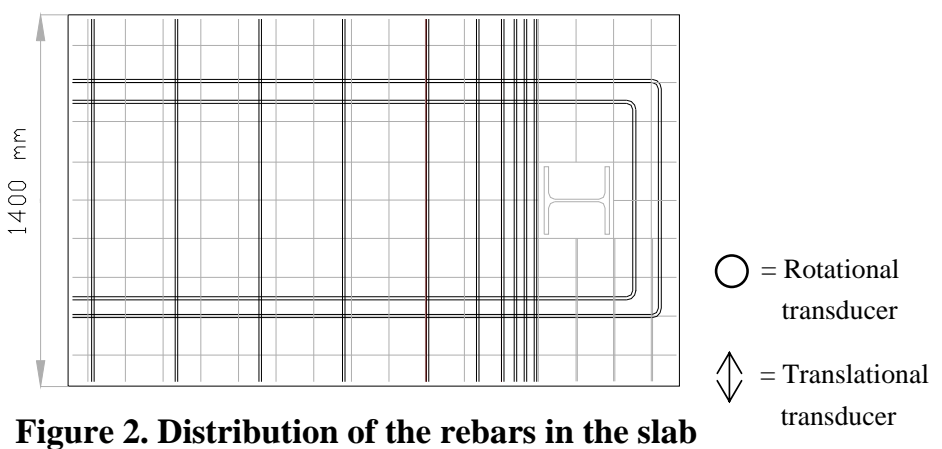


Compression tests on concrete cubes were performed on the same day as the experimentation on the joint specimens. Coupons have also been extracted from the different steel elements. All the measured mechanical properties for steel and concrete are reported in (Demonceau, 2008). Two independent measurement systems have been used to derive the moment-rotation curve of the joints: rotational and translational transducers, as shown in Fig. 3 (respectively circles and arrows). The objective of this rather complex instrumentation is to draw two independently measured joint moment-rotation curves, to compare them and, in the case of good agreement, to ensure the accuracy of the reported experimental results.

Fig. 3 presents the $M-\phi$ behavioural curves obtained for the monotonic test by means of the translational and rotational transducers measurements. In agreement with the Eurocodes, the moment is evaluated at the connection level. Main joint properties are listed in Table 1; the initial stiffness is estimated in the "unloadingreloading” part of the graph (see Fig. 3). During the test, first cracks in the concrete slab appeared i) transversally, close to connection and ii) longitudinally, just behind the column, as shown in Fig. 3 . The transversal cracks result from the tension forces in the longitudinal rebars while the longitudinal ones are due to shear forces. Then, at a higher loading step, new cracks developed until a shear failure occurred behind the column (hatched part in Fig. 3) for a bending moment of 201,6 kNm and a rotation of 31 mrad (less than the requested value of $35 \mathrm{mrad}$ ). In addition to these cracks, significant yielding developed in the steel joint components: column web panel in shear and end-plate in bending first, beam flange in compression and beam web in tension later on. Photographs of this test are given in Fig. 4. The test was stopped with the development of a crack in the beam web in the vicinity of the connection as illustrated in Fig. 4.

The shear failure of the concrete slab behind the column was not expected and had therefore not been considered in the design phase; the same collapse mode was observed during the cyclic test performed on the same joint configuration. Accordingly, a new collapse mode for this configuration of joint was identified
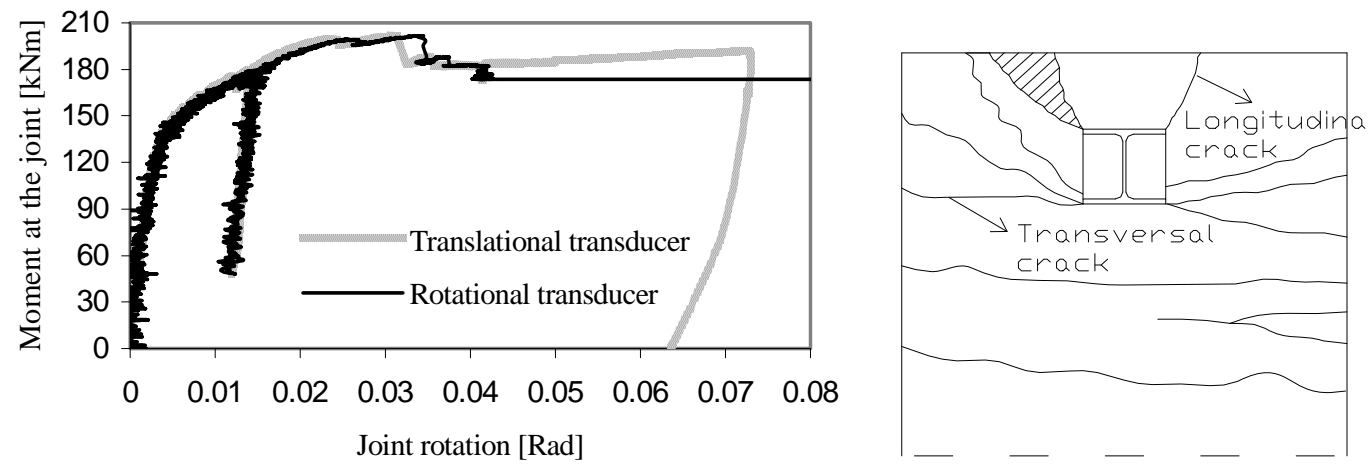

Figure 3. Moment-rotation curves for the tested single-sided composite joint with the distribution of the cracks at the end of the test 

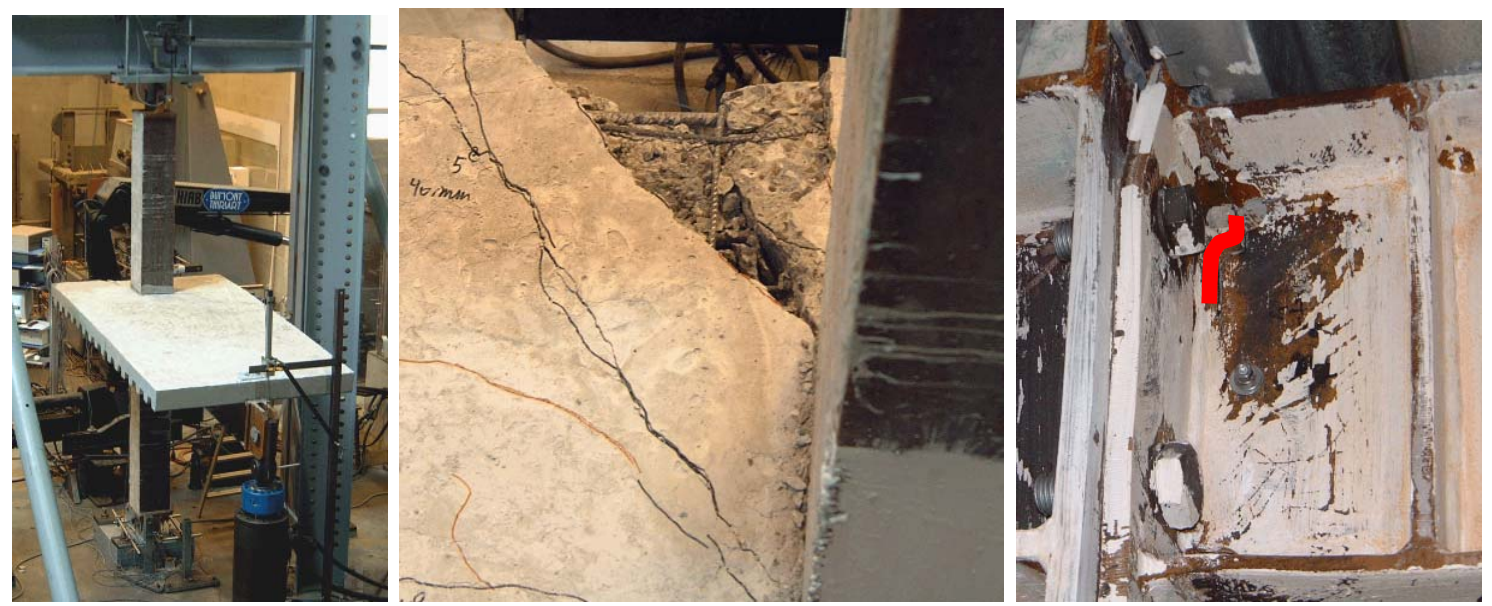

Figure 4. Photos of the joint at the end of the test

Table 1. Main mechanical properties of the joint (defined in Fig. 9)

\begin{tabular}{l|c}
\hline & Test results \\
\hline Initial rotational stiffness $S_{j, \text { ini }}[\mathrm{kNm} / \mathrm{rad}]$ & \pm 65000 \\
Ultimate bending moment $M_{u}[\mathrm{kNm}]$ & 201,58 \\
Rotation $\phi_{u}[\mathrm{rad}]$ reached at $M_{u}[\mathrm{kNm}]$ & 0,031 \\
\hline
\end{tabular}

\subsubsection{Experimental tests performed at the University of Trento}

The experimental tests which have been performed within the European project "PRECIOUS" at the University of Trento on Type 1 joint at room temperature are described herein (Bursi et al, 2008). The two configurations which were tested are: single-sided beam-to-column composite joints with partially encased composite columns and composite slabs (Configuration A) and single-sided beam-to-column composite joints with partially encased composite columns and concrete slabs casted on prefabricated pre-slab (Configuration B).

The beams are made of IPE300 profiles with the upper flange connected to the composite or concrete slab (full connection); the columns are partially encased HEB260 profiles. The materials were ordered as follows: S355 steel for the profiles and the end-plates, ductile S450C steel for the rebars and C25/30 for the concrete. The bolts are M24, grade 10.9. More details and in particular the actual properties of the materials are available in (Bursi et al, 2008) or in (Demonceau, 2008). The joint configuration presented herein is closed to the one tested in Liege (see previous paragraph); only one upper bolt row has been added in the tests of Trento to have a bolt row within the concrete slab which is protected in case of fire.

These joints were tested under monotonic and cyclic loadings; however, only Configuration A was tested under monotonic hogging moments. Accordingly, only this test will be considered herein (see Fig. 5). 

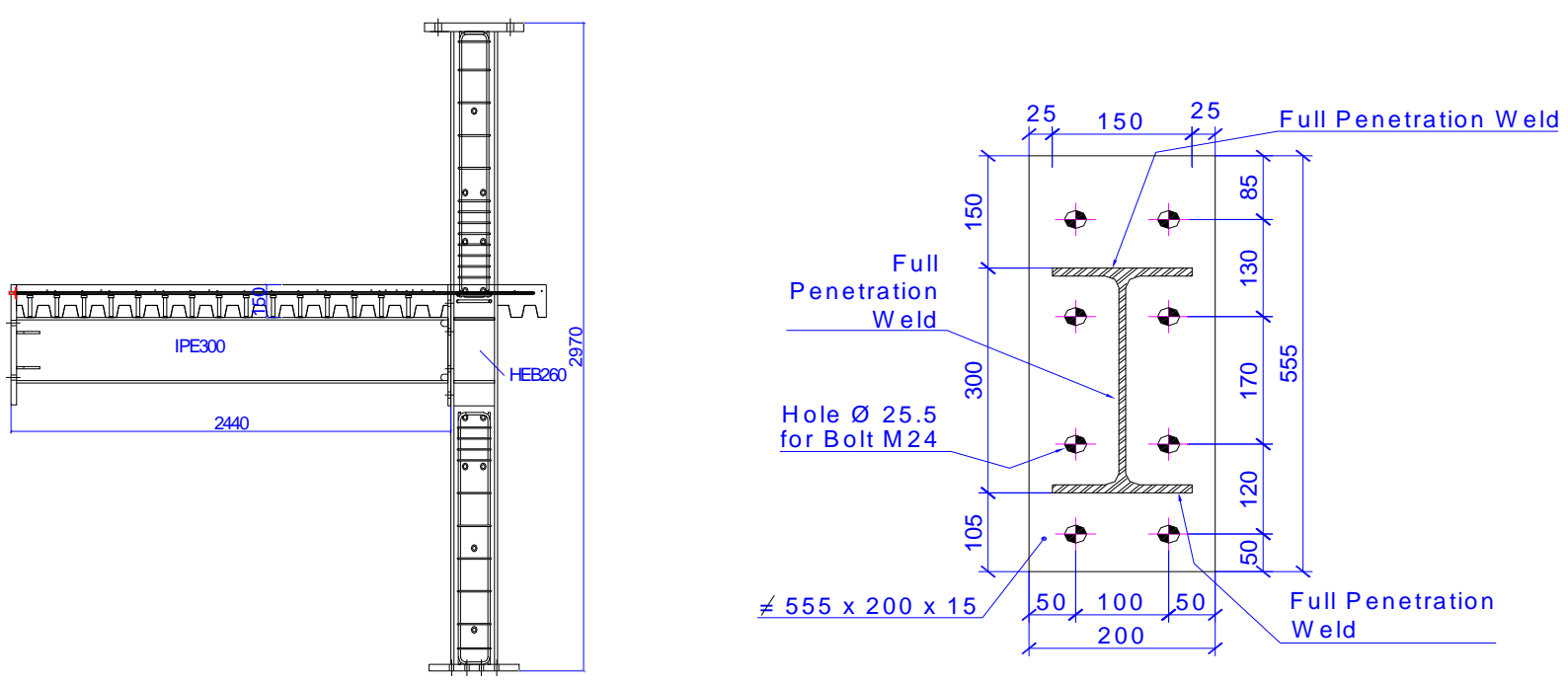

Figure 5. Joint configuration A tested at the University of Trento (Trento, 2006)

The moment-rotation curve is given in Fig. 6. During the test, the development of cracks was observed in the concrete slab in the vicinity of the column; in particular, cracks with an inclination of $45^{\circ}$ were observed behind the column (see Fig. 7) which is a clear indication of the "strut-and-tie” behaviour within the slab. In parallel, yielding developed in some steel components (mainly column web in shear and beam flange in compression) with non-negligible deformations of the latter (see Fig. 8). In Fig. 6, a loss of resistance is observed for a rotation of more or less 50 mrad in the moment-rotation curve; this loss of resistance is associated to the concrete slab crushing in the vicinity of the column induced by the development of the "strut-and-tie" behaviour. The main properties of the tested joint are summarised in Table 2.

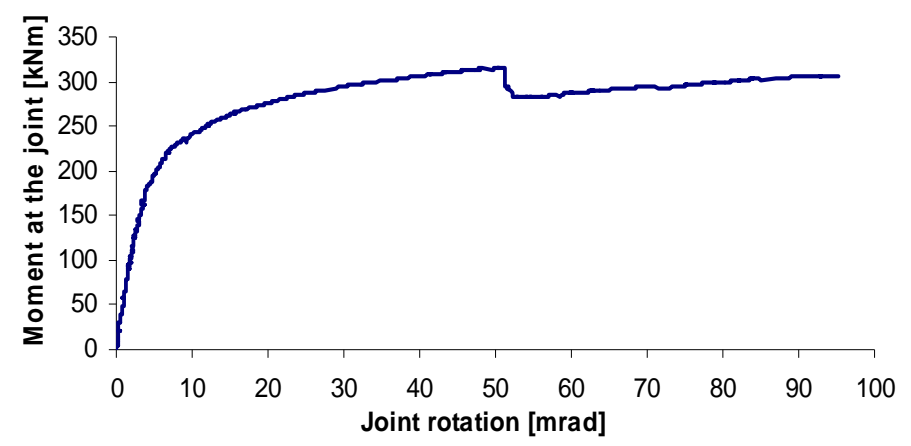

Figure 6. Experimental moment-rotation curve of the joint 


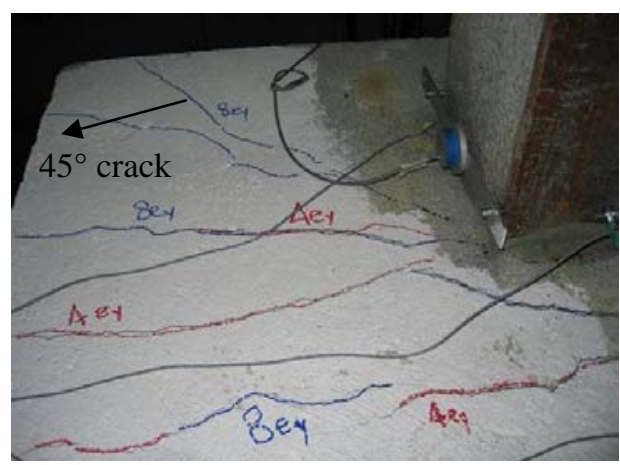

Left side

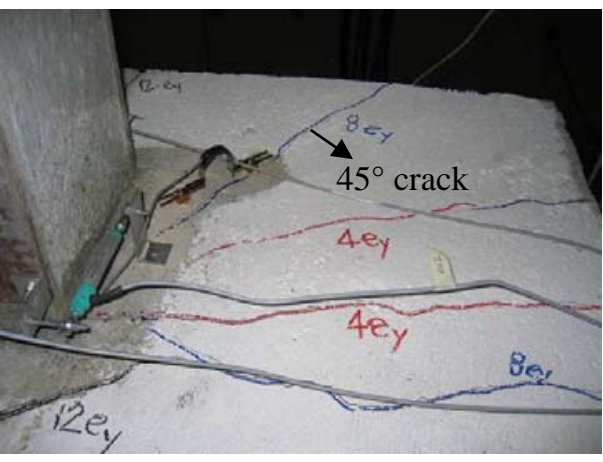

Right side

Figure 7. Test 1 - Development of cracks in the composite slabs (at the end of the test) (Trento, 2006)

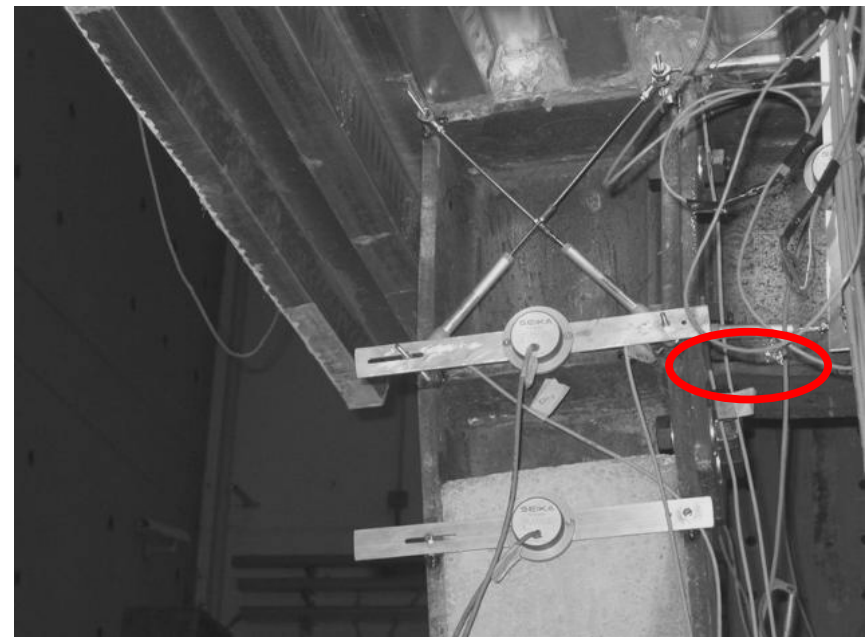

Figure 8. Test 1 - Deformation of the steel components at the end of the test (Trento, 2006)

Table 2. Main mechanical properties of the tested joint (defined in Fig. 9)

\begin{tabular}{l|c}
\hline & Test results \\
\hline Initial rotational stiffness $S_{j, \text { ini }}[\mathrm{kNm} / \mathrm{rad}]$ & \pm 57450 \\
Ultimate bending moment $M_{u}[\mathrm{kNm}]$ & 316 \\
Rotation $\phi_{u}[\mathrm{rad}]$ reached at $M_{u}[\mathrm{kNm}]$ & 0,051
\end{tabular}

\subsection{Analytical model for the characterisation of composite joints at room temperature}

In the previous paragraphs, two tests on composite joints subjected to hogging moments have been presented.

The validity of the component method, which is recommended in the Eurocodes to characterise the mechanical properties of the joints, is investigated in this paragraph through comparisons between the moment-rotation curves analytically predicted and the ones experimentally determined.

This method considers any joint as a set of individual basic components. Each of these basic components possesses its own strength and stiffness either in tension or in compression or in shear. The coexistence of 
several components within the same joint element can obviously lead to stress interactions that are likely to decrease the resistance of the individual basic components; this effect is taken into account within the method.

The application of the component method requires the following steps:

- $\quad$ identification of the active components in the joint;

- $\quad$ evaluation of the stiffness and/or resistance characteristics for each individual basic component (specific characteristics - initial stiffness, design resistance, ... - or the whole deformability curve);

- assembly of all the constituent components and evaluation of the stiffness and/or resistance characteristics of the whole joint (specific characteristics - initial stiffness, design resistance, ... - or the whole deformability curve).

The component method as actually proposed in the Eurocodes only permits to compute the design bending resistance $M_{R d}$ and the initial stiffness $S_{j, i n i}$. In order to be able to compare the moment-rotation curve until the ultimate moment $M_{u}$, it is also needed to compute the post-limit stiffness $S_{j, \text { post-limit, }}$ the ultimate bending resistance $M_{u}$ and the rotation $\phi_{u}$ (see Fig. 9); the latter has been computed according to the method proposed in (Jaspart, 1991) which is in full agreement with the component method, as implemented in the Eurocodes.

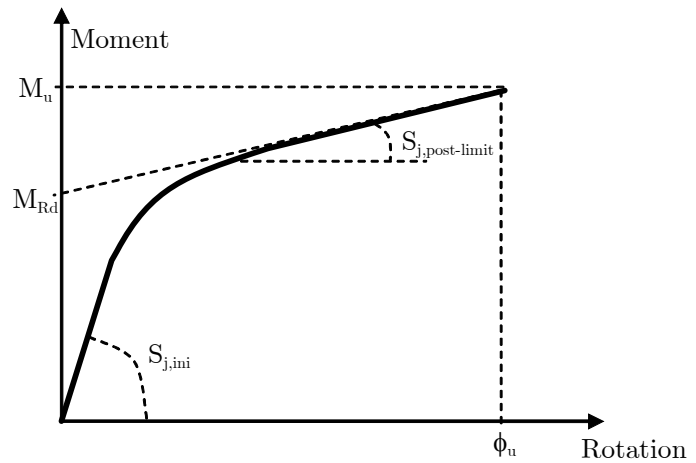

Figure 9. M- $\phi$ behaviour curve of a joint

For the analytical predictions, the material properties which are used are the actual ones, i.e. the ones obtained through coupon tests. Part of the component characterisation has been realised with two softwares: CoP (www.connectionprogram.com), dedicated to the computation of steel joints (under bending moments and axial loads) and developed by the University of Liege and the F+W design office, and a homemade software based on an Excel sheet dedicated to the computation of composite joints with bolted end-plates (Demonceau, 2008).

\subsubsection{First comparison - University of Liege test}

The comparison of the moment-rotation curves is given in Fig. 10. The component method prediction has been obtained by applying the rules as recommended in (Eurocode 3-1-8, 2005) and (Eurocode 4-1-1, 2004). 
The failure mode associated to the analytically predicted resistant and ultimate bending moments involves two components: “rebars in tension” and "end-plate in bending”. From Fig. 10, it can be observed that the initial and the strain hardening stiffnesses are well estimated while the resistant and ultimate bending moments and the ultimate rotation are overestimated with the analytical approach.

The observation during the experimental test can explain this difference. As already stated, first cracks developed in the concrete slab, transversally in the vicinity of the connection and longitudinally just behind the column (see Fig. 3). The transverse cracks are due to the tension forces acting in the longitudinal rebars (each side of the column); this failure mode is covered by Eurocode 4 ("slab rebars in tension” component). But nothing is said in the normative documents as far as longitudinal shear cracks are concerned. Actually, Eurocode 4 only prescribes a minimum section area for the transversal rebars to be placed behind the column (see Eq. (6) here below) so as to avoid the crushing of the concrete slab against the column when the joint is subjected to hogging moments.

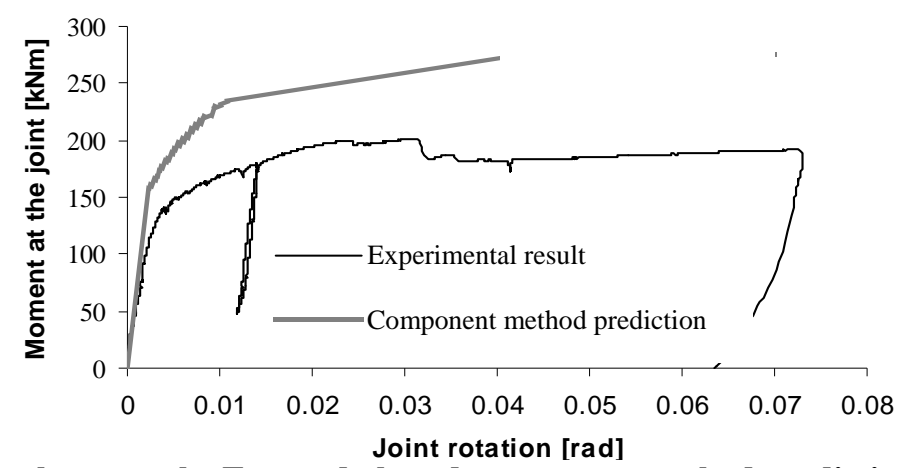

Figure 10. Comparison between the Eurocode-based component method prediction and the experimental test result obtained in Liège

In reality, as soon as the longitudinal cracks in shear develop, the concrete does not contributes anymore to the slab resistance. The transversal rebars are thus alone to resist the forces acting along these cracks. These forces can be divided in two parts (Fig. 11): tension forces resulting from the "strut-and-tie" behaviour within the slab and shear forces induced by the longitudinal rebars in tension.

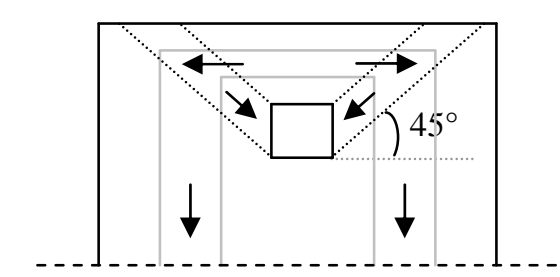

Tension ("strut-and-tie behaviour”)

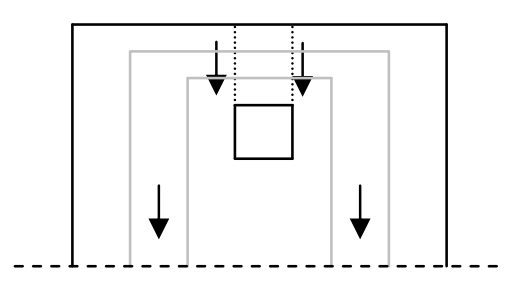

Shear forces

Figure 11. Forces acting along the shear cracks in the slab

Obviously, an interaction between the tension and the shear forces has to be considered. So, the resistance criteria, which may be roughly estimated by means of the Von Mises criterion, can be expressed as follows: 


$$
\sqrt{\left(\sigma^{2}+3 \tau^{2}\right)} \leq f_{s k}
$$

where $\sigma$ are the tension stresses induced by the "strut-and-tie" behaviour, $\tau$, the shear stresses induced by the shear forces and $f_{s k}$, the yield strength of the rebars.

In the present case, the compression struts are assumed to be inclined by $45^{\circ}$ (see Fig. 11), which is close to the reality (observation coming from tests - see (Doneux, 2002), (Ferrario, 2004) and (Demonceau, 2008)) ; the tension and shear stresses are then equal $(\sigma=\tau)$ and Eq. (1) becomes:

$$
\sigma \leq f_{s k} / 2
$$

According to Eq. (2), half of the resistance is allocated to tension and half to shear. To take this into account, a modification of the procedure to predict the resistance of the rebars is suggested here below for single-sided joint configurations.

In (Eurocode 4-1-1, 2004), the resistance of the component "slab rebars in tension” is defined as:

$$
F_{R d, 13}=\frac{A_{s} f_{s k}}{\gamma_{s}}
$$

where $A_{s}$ is the total area of the longitudinal slab rebars in tension with a diameter higher than $6 \mathrm{~mm}$ and $\gamma_{s}$, the safety coefficient to be applied to the rebar material (equal to 1,15). As previously mentioned, this formula only considers the resistance of the longitudinal rebars.

The formula which is suggested, to include the shear-tension interaction, is the following:

$$
F_{R d, 13}=\min \left[\frac{A_{s} f_{s k}}{\gamma_{s}} ; \frac{2 A_{s, 2}\left(f_{s k} / 2\right)}{\gamma_{s}}\right]
$$

where $A_{s, 2}$ is the total area of the transverse slab rebars behind the column. The factor "2" in front of $A_{s, 2}$ is justified by the presence of two sections of failure (one at each side of the column - Fig. 11).

So, the resistance of the component "rebars in tension" is governed by the weakest of the loaded rebars, longitudinal or transversal.

Another solution would be to define new requirements for the minimum area of transverse rebars to be placed behind the column so as to avoid the failure of the concrete slab behind the column (by assuming a truss rod inclination of $\left.45^{\circ}\right)$ :

$$
A_{S, 2} \geq A_{S}
$$

instead of:

$$
A_{s, 2} \geq \frac{A_{s}}{2}
$$


as actually stated in (Eurocode 4-1-1, 2004) for such joint configurations.

The computed moment-rotation curve obtained through the component method by substituting Eq. (4) to Eq. (3) for the evaluation of the resistance of the "slab rebars in tension” component is given in Fig. 12. Key values are reported in Table 3. Two assumptions have been used to perform the computations as far as the area of the rebars is concerned: total area of the rebars $\left(A_{s, t o t}\right)$ or area of the rebars with a diameter higher than 6 mm only, as recommended in Eurocode $4\left(A_{s, 12 \mathrm{~mm}}\right)$.

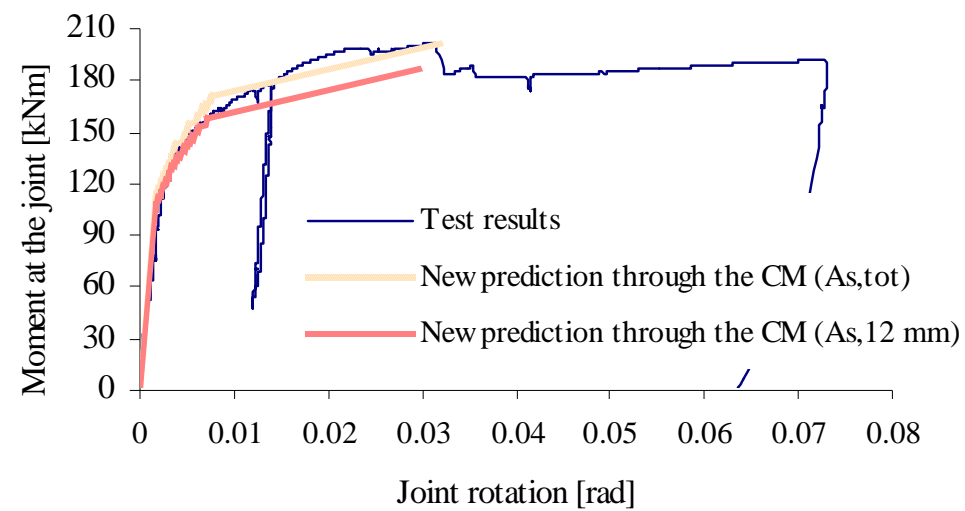

Figure 12. Comparison between the "new" component method predictions and the experimental test result

Table 3. Key values obtained experimentally and analytically through the new prediction approach

\begin{tabular}{l|ccc} 
& Exp. results & New formula: $\boldsymbol{A}_{\boldsymbol{s}, \text { tot }}$ & New formula: $\boldsymbol{A}_{\boldsymbol{s}, \mathbf{1 2} \mathbf{~ m m}}$ \\
\hline$S_{j, \text { ini }}[\mathrm{kNm} / \mathrm{rad})$ & 65000 & 64312 & 64312 \\
$M_{u}[\mathrm{kNm})$ & 201,58 & 201,54 & 186,4 \\
$\phi_{u}[\mathrm{rad})$ & 0,031 & 0,032 & 0,030 \\
\hline
\end{tabular}

Fig. 12 and Table 3 show the good agreements between the test results and the component method predictions using the new resistance formula for the "slab rebars in tension" component. Also, it can be observed that the loss of resistance at a rotation of more or less 0,031 rad can be justified by the collapse of the 6 mm rebars; indeed, the experimental curve at this rotation passes from the " $A_{s, t o t}$ " analytical curve to the " $A_{s, 12 m m}$ " curve. This is confirmed by Fig. 12 where it can be seen that the $6 \mathrm{~mm}$ transversal rebars behind the column are broken at the end of the test (the concrete slab has been carefully removed to inspect the rebars). This difference in behaviour is due to the lower ductility of the $6 \mathrm{~mm}$ rebars of the mesh compared to that of the $12 \mathrm{~mm}$ bars. It is the reason why Eurocode 4 recommends that the rebars to be considered in the joint calculation are only those with a diameter higher than $6 \mathrm{~mm}$. 


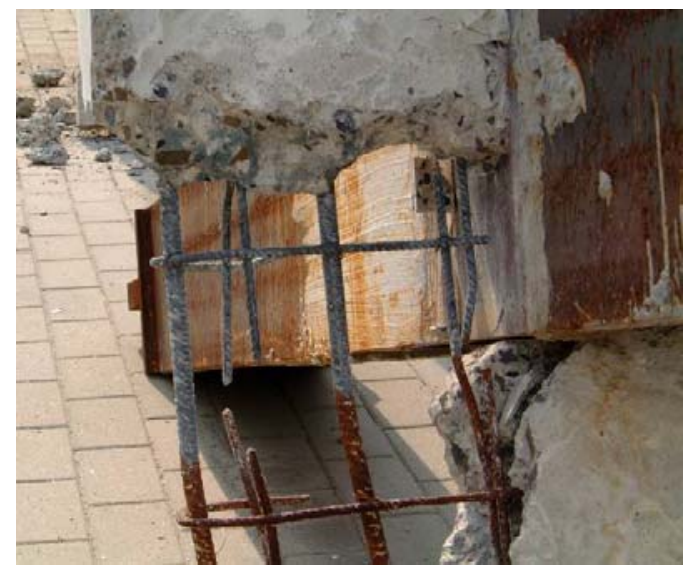

Figure 12. Photo of the rebars behind the column at the end of the test

Remark: In the tests on double-sided composite joint configurations performed by other partners involved in the above-mentioned "SWAY FRAMES" project (Bitar et al, 2006), the occurrence of shear cracks in the concrete slab has not been observed. This can be explained by the amount of concrete available behind the column to resist to the shear loads that is higher than in a single-sided joint configuration.

\subsubsection{Second comparison - University of Trento test}

The analytical characterisation of the joint has been performed through the component method, as recommended in the Eurocodes (i.e. with Eq. (3) - namely "Present" method) and with the new proposal presented in the previous section (i.e. with Eq. (4) - namely "New" method). All the rebars are considered in the computation, i.e. rebars with a diameter of $12 \mathrm{~mm}$ and $6 \mathrm{~mm}$. The obtained results with the "present" and the "new" methods are presented in Table 4. The analytically determined collapse mode associated to the resistant and ultimate bending moments is "Beam flange in compression" with the two methods, which is in good agreement with the experimental test observations. Even if the component "Rebars in tension” is not directly involved in the collapse mode, it can be seen that the obtained results with the two methods are significantly different. It can be justified by the fact that the distribution of the internal forces amongst the rows of bolts (and, accordingly, the moments) is affected by the maximum load which can be supported by the rebars.

Table 4. Computed resistant and ultimate bending moments with the two methods and comparison to the experimental test results

\begin{tabular}{|c|c|c|c|c|}
\hline Methods & $\mathrm{M}_{\mathrm{Rd}}[\mathrm{kNm}]$ & $\mathrm{M}_{\mathrm{u}}[\mathrm{kNm}]$ & $\mathbf{M}_{\mathrm{u}, \exp .}[\mathrm{kNm}]$ & Difference \\
\hline "Present” method & 319,1 & 391,0 & 316 & $+24 \%$ \\
\hline “New” method & 272,5 & 335,8 & 316 & $+6 \%$ \\
\hline Difference & $-14,6 \%$ & $-14,1 \%$ & & \\
\hline
\end{tabular}

Through the comparison between the analytical predictions and the experimental results given in Fig. 13 and in Table 4, it can be observed that the ultimate moment obtained with the "Present" method is widely overestimated 
(difference of $24 \%$ ) while the one obtained with the "new" method is more accurate (difference of $6 \%$ ). The experimental curve and the analytical curve obtained with the new method are in very good agreement until a joint rotation of more or less 51 mrad. After this, a loss of resistance of the joint is observed for the experimental result which is linked to a concrete crushing (associated to a lack of ductility) in the "strut-and-tie" behaviour; this phenomenon is not yet taken into account in the component method. Additional investigations should be realised in the future in order to characterise this phenomenon which can limit the value of the resistant and/or ultimate bending moments and the rotation capacity.

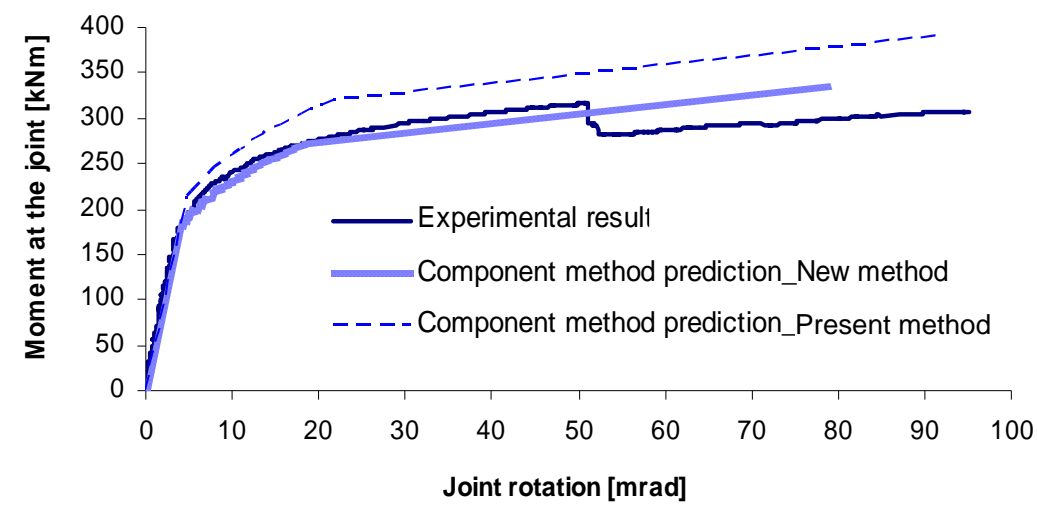

Figure 13. Comparison between the component method predictions and the experimental test result obtained at Trento

\section{Behaviour of composite beam-to-partially encased column joints at elevated temperature}

\subsection{Description of the fire tests and numerical simulations}

As part of the PRECIOUS project, BRE performed a series of six fire tests on sub-structures with the aim of evaluating the mechanical behaviour of extended end-plate connections under fire after an earthquake (Lennon, 2008). Four tests were undertaken on internal beam-to-column joints and two tests dealt with single-sided beamto-column joints. The specimens tested under fire are not those that had been previously subjected to seismic loading; indeed, before the fire tests, the specimens have been subjected to an equivalent static loading inducing similar damages than the dynamic loading resulting from a moderate earthquake $(0,4 \mathrm{~g})$. In this paper, the modelling and the analysis of the two tests performed on the single-sided joints (Configuration B - see $\S 2.1 .2$ ) are presented. The only difference between the two tests is related to the type of slab: Test F1-3 - Profiled steel sheeting and Test F1-6 - Flat slab on pre-slab.

The geometry of the tested joint is identical to the one described in Fig. 5 for the tests at room temperature; the applied bending moment is constant during the complete test under ISO fire. The value of the applied bending moment has been determined through the analysis of a complete frame submitted to the vertical loads 
recommended in the European norms (EN 1991-1-1; 2002). With partial safety factors equal to 1, this applied bending moment is approximately equal to $20 \%$ of the plastic resisting moment $\mathrm{M}_{\mathrm{Rd}}$ at room temperature. Concrete spalling in the slab and the encased column or local buckling of the bottom beam flange have been observed but no catastrophic failure was observed during the one-hour fire tests so that the ability of this type of joint to survive a fire following a moderate earthquake has been demonstrated experimentally. The presence of dissipative zones for the absorption of energy under seismic actions allows a ductile behaviour at the fire limit state. The capacity of the bolt row located in the concrete slab (see Fig. 5) to resist the shear capacity during the fire results in an enhancement of the performance of the joint at the fire limit state.

The distribution of temperature in the joint has been simulated by means of the finite element program SAFIR (Franssen, 2005). The convection coefficients and relative emissivity values used in numerical thermal simulations are taken from Eurocode 3 (prEN 1993-1-2, 2004). As allowed in this document, the shadow effect in the concave parts of the joint zone is taken into account: the emissivity of steel is multiplied by shadow factors calculated here for three different zones (see Fig. 14 - more details in (Bursi and al., 2009)).
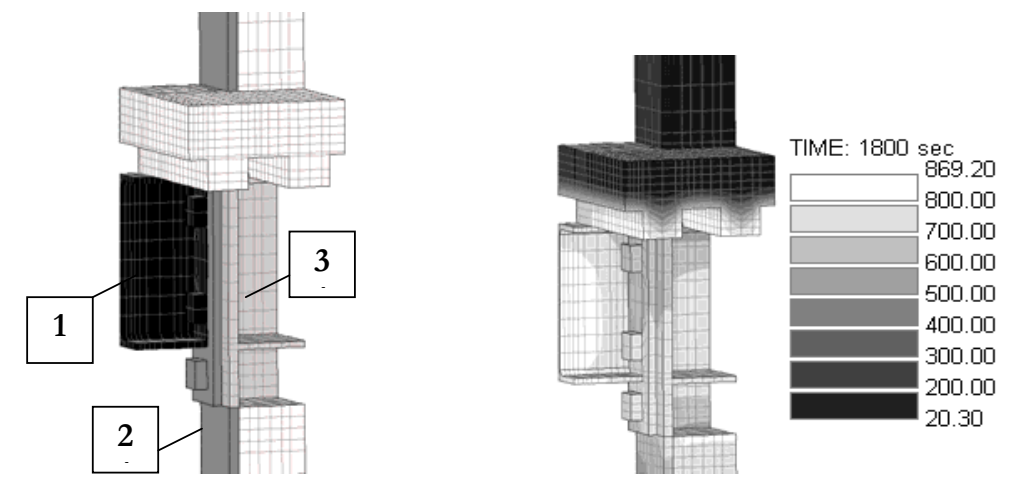

Figure 14. Test F1-3 (a) Zones for shadow factors - (b) Thermal distribution in the joint under ISO fire after 30 minutes

During the experimental tests, some significant differences between symmetrically located thermocouples have been observed, supposedly because of the position of the burners, especially in the Test F1-6. However, the comparisons between numerical and experimental results validate the thermal model, as shown in Fig. 15. The respective positions of thermocouples $(10,13)$ and $(23,26)$ are symmetrical and identical temperatures should have theoretically been measured. 

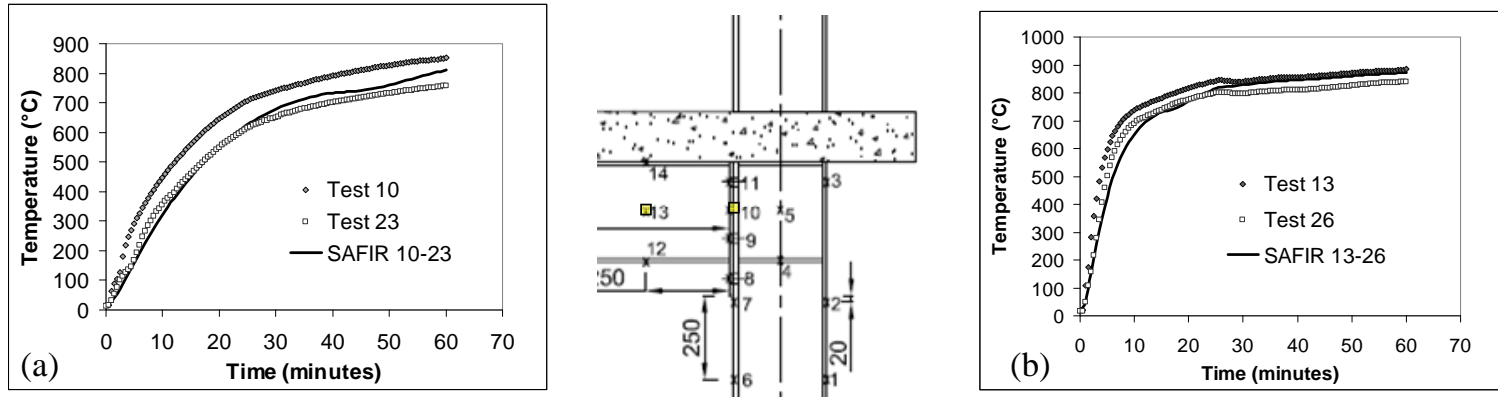

Figure 15. Test F1-3 (a) Temperature in the end-plate - (b) Temperature in the beam web
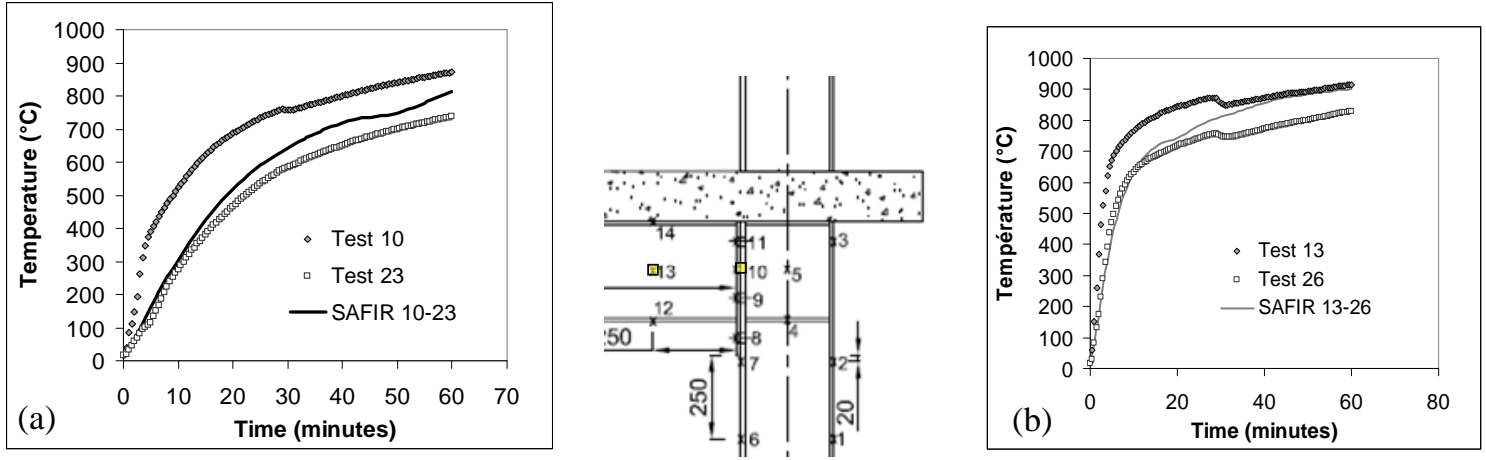

Figure 16. Test F1-6 (a) Temperature in the end-plate - (b) Temperature in the beam web

\subsection{Evaluation of thermal distribution under fire loading}

\subsubsection{Parametrical Analyses}

The influence of three parameters on the distribution of temperature in the joint under an ISO fire has been investigated with the validated finite element model: the column profile type, the plate thickness and the presence of bolts. The reference case is a composite joint with a $15 \mathrm{~cm}$ thick concrete slab (constant thickness), an IPE 300 steel beam, a HEB 280 steel column and two horizontal stiffeners for the column web. The comparison of temperature distributions according to each parameter has been realised on the basis of the distribution of temperature along the plate height across the bolts (see Fig. 17) because the temperature of the plate is almost constant on each horizontal section.

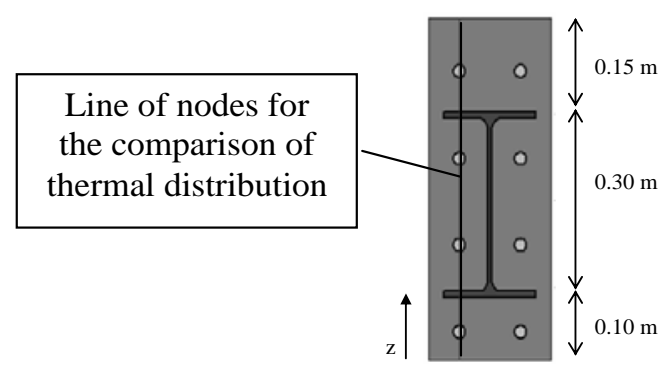

Figure 17. Geometry of the extended end-plate connection and reference line for thermal distribution in the joint 
Fig. 18, 19 and 20 show that the column type, the plate thickness and the presence of bolts have no significant influence on the thermal distribution in the end-plate under an ISO fire. The differences of temperature between the cases of this parametric analysis are lower after 30 minutes than after 15 minutes.
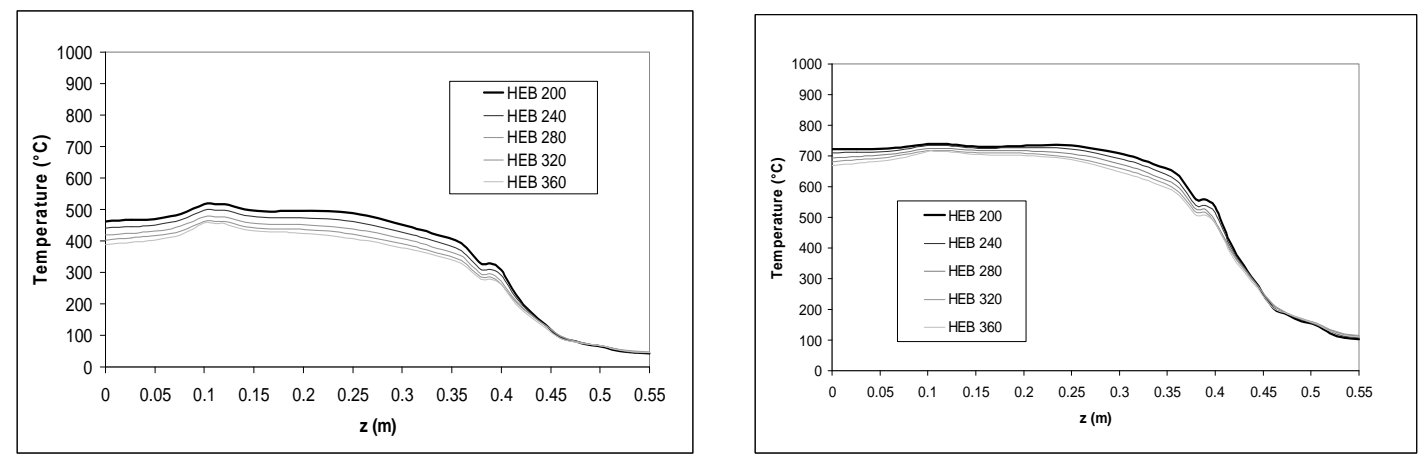

Figure 18. Influence of the column type on temperature distribution - (a) after 15 minutes (b) after 30 minutes
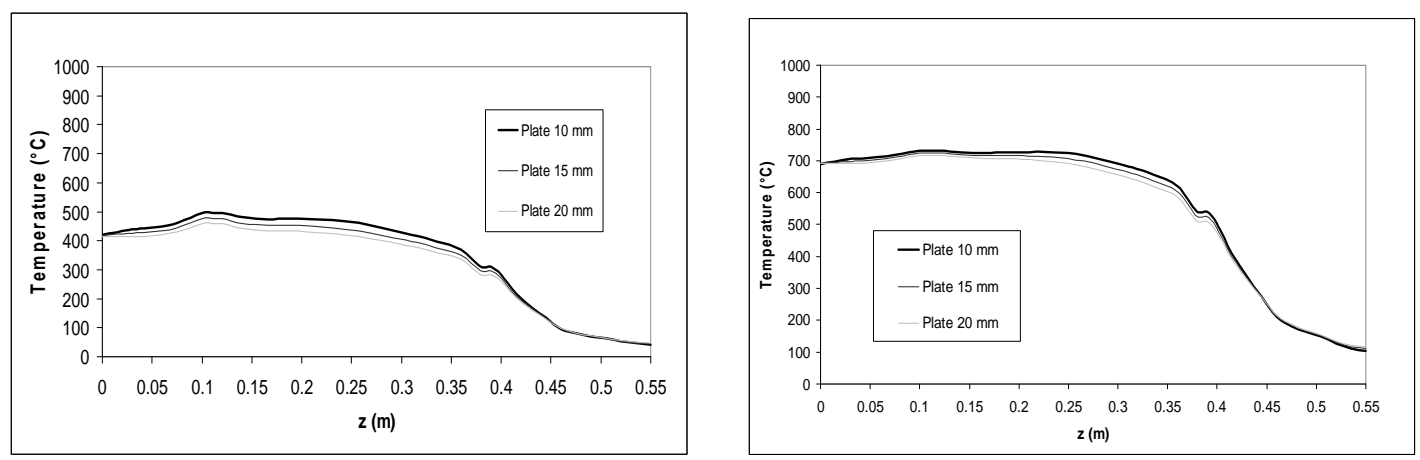

Figure 19. Influence of the plate thickness on temperature distribution - (a) after 15 minutes (b) after 30 minutes
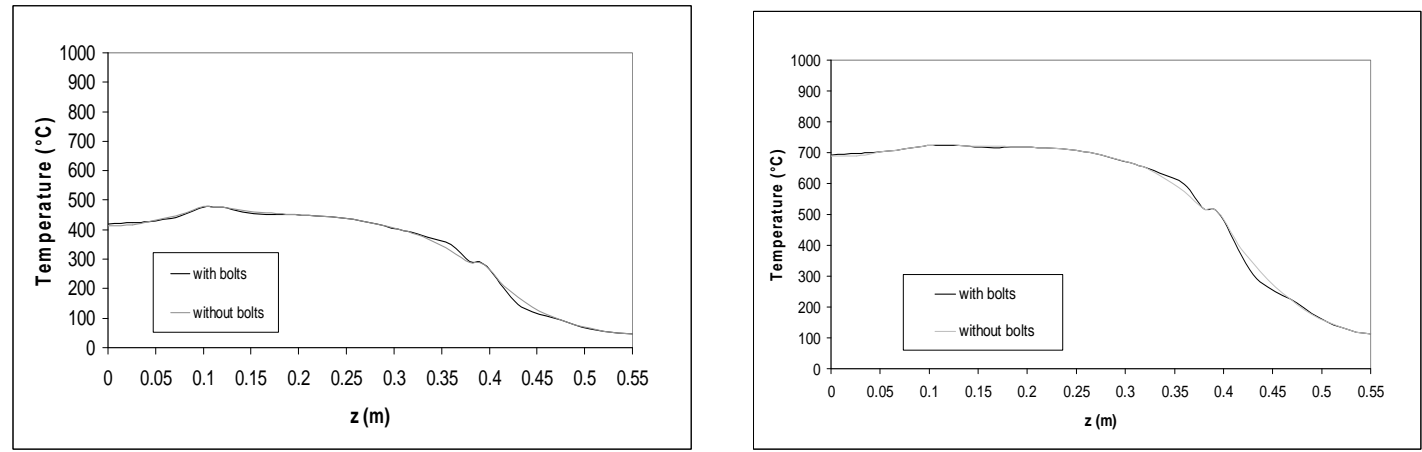

Figure 20. Influence of the presence of bolts on temperature distribution - (a) after 15 minutes (b) after 30 minutes

\subsubsection{Simple procedure for prediction of temperature in the joint}

In this section, a simple method is proposed to predict the evolution of temperature in the steel components of the here-studied composite joint.

A method for the determination of the temperature in a steel beam covered by a slab on its top flange is given in

EN 1993-1-2. It is based on the assumption that the temperature is uniform in the steel section during heating. By integrating formula (7), it is possible to determine the steel temperature as a function of time. 


$$
\Delta \theta_{a}=k_{\text {sh }} \dot{h}_{\text {net }} \cdot \frac{1}{c_{a} \rho_{a}} \cdot \frac{A_{m}}{F} \Delta t
$$

For the temperature within the end-plate (see Fig. 3), the following procedure is proposed:

Step 1

The temperature $T_{1}$ in the bottom flange of the beam is obtained with the above-mentioned Eurocode formula with the Am/F ratio of the I-section and without considering any $\mathrm{k}_{\mathrm{sh}}$. The shadow effect is not considered here.

\section{$\underline{\text { Step } 2}$}

Due to the presence of more material in the joint zone, the temperature at the junction between the lower flange and the plate $\mathrm{T}_{2}$ may be obtained by the use of a coefficient $\eta_{\text {joint }}$ :

$$
T_{2}=20+\frac{\left(T_{1}-20\right)}{\eta_{\text {joint }}} \quad ; \quad \begin{array}{lll}
\eta_{j \text { oint }}=0.004 t^{2}-0.17 t+3 & \text { if } \quad t \in[0,20] \\
\eta_{\text {joint }}=1+0.005(60-t) & \text { if } \quad t \in[20,60]
\end{array} \quad \text { ( } \text { in minutes) }
$$

In particular, $1 / \eta_{\text {joint }}$ is equal to $1.35,1.15$ and 1 after 15,30 and 60 minutes.

\section{$\underline{\text { Step } 3}$}

The shadow coefficient $\eta_{\text {shadow }}$ and temperature $T_{3}$ at the junction of the upper flange of the beam and the plate are given by:

$$
T_{3}=20+\frac{\left(T_{2}-20\right)}{\eta_{\text {shadow }}} \quad ; \quad \eta_{\text {shadow }}=0.0003 t^{2}-0.033 t+2.23 \quad \text { if } \quad t \in[0,60]
$$

In particular, $1 / \eta_{\text {shadow }}$ is equal to $1.8,1.5$ and 1.33 after 15,30 and 60 minutes.

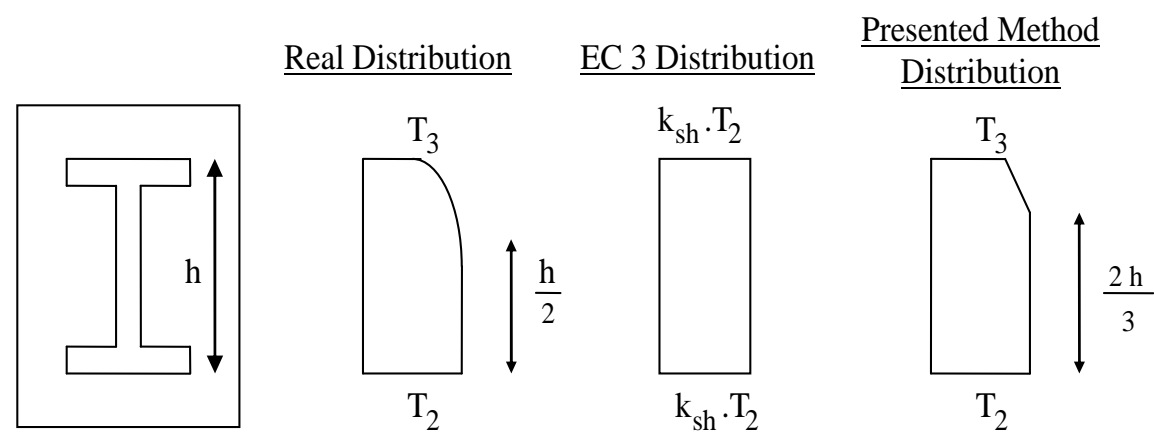

Figure 21. Temperature distribution in the end-plate between beam flanges

\section{$\underline{\text { Step } 4}$}

The temperature of the plate in the concrete slab decreases according to an exponential function in the slab. The general formula chosen is:

$$
T_{\text {plate-slab, } x}=20+\left(T_{3}-20\right) e^{-\alpha x}
$$

$\alpha$ is a time-dependant coefficient; 
$\mathrm{x}$ is the distance between the point considered and the bottom surface of the slab.

The expression of $\alpha$ in function of time is:

$$
\alpha=60 t^{-0.46}
$$

In particular, $\alpha$ is equal to $17.25,12.55$ and 9.12 after 15,30 and 60 minutes.

The comparisons between analytical and numerical results are given for the complete height of the plate after 15, 30 and 60 minutes, making the safe assumption that $\mathrm{T}=\mathrm{T}_{2}$ in the part of the plate situated below the beam:
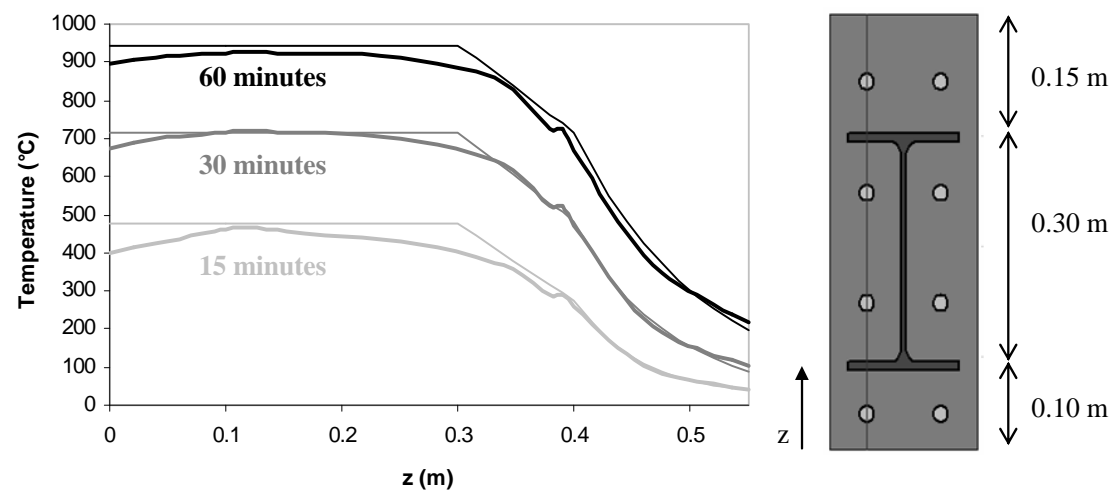

Figure 22. Comparison between numerical and analytical temperatures in the studied joint under ISO fire For the other joint components, the temperature is assumed to be the identical in all the components situated at a same vertical level (beam, end-plate, bolt, column). The rebars embedded in the concrete near the joint have the same temperature as the end-plate.

\subsection{Mechanical response of the joint during fire}

The calculation of the mechanical behaviour of the joint at elevated temperature follows exactly the same procedure as at ambient temperature. The evaluation of the resistance and the stiffness of the joints under fire loading have been calculated at each time step on the basis of the thermal distribution and using the component method. The extension of this method to elevated temperatures consists in multiplying the resistance and the Young modulus of steel by reduction coefficients defined in EN 1993-1-2. The validity of this extension has already been demonstrated by Simões da Silva and al. (Simões, 2001) for steel joints.

During the fire tests, the vertical displacement at the composite beam extremity has been measured in order to obtain the evolution of the joint rotation. This vertical displacement is due to the superposition of two effects: the joint rotation and the beam deflection (see Fig. 23). In the presented calculations, the rotation of the joint is evaluated analytically with the use of the adapted component method (using the new formulas proposed in $\S 2.2 .1$ for the component "rebars in tension”) and the beam deflection has been determined by numerical simulations in the finite element program SAFIR. In the case of steel sheeting slab, the presence of ribs is neglected and the 
thermal protection provided by ribs and steel sheeting was not considered. The temperatures used in the component method are extracted from the numerical simulations.

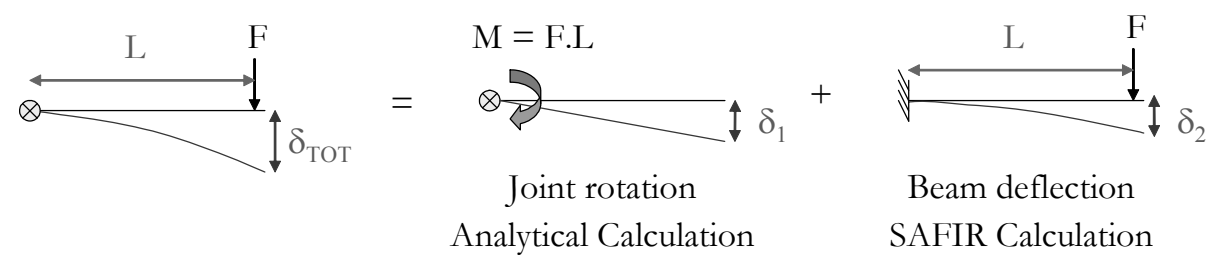

Figure 23. Joint and beam contributions to the beam extremity vertical displacement

The experimental results of the tests F1-3 (concrete slabs casted on prefabricated pre-dalles and F1-6 (steel sheeting slab) performed on single-sided joints have been compared with the analytical calculations. The process mentioned above has been implemented in an automatic procedure where reduction factors on components resistance and stiffness are calculated from the temperature in the different joint zones. The design resisting bending moment, ultimate bending moment, initial stiffness and the post-critical stiffness are automatically calculated and the capacity of rotation is deduced from the method proposed in (Jaspart, 1991) at each time step (see Fig. 9). During the two tests, the resistance of the component "bottom flange in compression" decreases rapidly while the resistance of the reinforcing bars and the bolts located in the concrete slab remains constant. Consequently, the position of the neutral axis moves to a higher position and additional compression components can be activated in the beam web and in the beam upper flange (see Fig. 24).

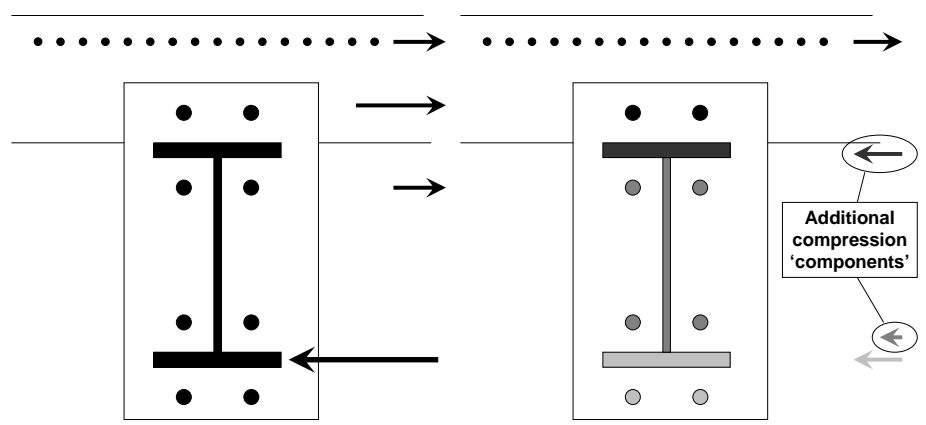

Figure 24. Distribution of internal forces in the joint at ambient temperature (a) and high temperatures

(b)

This leads to the definition of two additional compression components: the "beam web in compression" and the "beam top flange in compression". However, the component "beam web in compression" is limited by the residual shear resistance of the beam web:

$$
\begin{aligned}
& F_{R d, \text { comp }, w e b}=\frac{x t_{w b} f_{y, w c}}{\gamma_{M, 0}} \\
& V_{w p}=\frac{0.9 f_{y, w c} A_{v c}}{\sqrt{3} \gamma_{M, 0}}+\frac{4 M_{p l, f c, R d}}{h_{c}-t_{f c}} \\
& F_{R d, \text { comp bottom flange }}+F_{R d, c o m p, w e b} \leq V_{w p}
\end{aligned}
$$


In Eq. (12), the parameter “ $x$ ” represents the height of the web in compression. The reduction factors (associated to the high temperature) on the resistance are not reported in Eq. (12) but have to be considered. The component “upper flange in compression” can not be activated if the bolt row situated below the top flange is in tension.

In test F1-6, the applied bending moment in the joint $(55.13 \mathrm{kN}$.m) remains lower than the design resisting moment during the complete duration of the test. Fig. 25 shows the good agreement between the vertical displacements at the extremity of the composite beam measured during the test and those predicted analytically. The behaviour of the joints has been studied with the use of bilinear and non-linear moment-curvature laws. The latter one correlates better but requests more complex calculations.

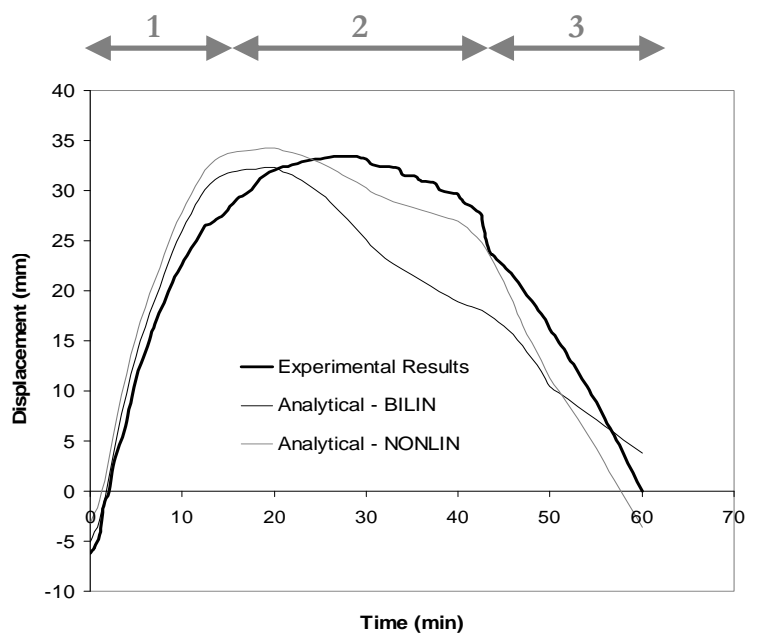

\section{1 : Thermal effect only \\ 2 : Elastic behaviour \\ 3 : Non-linear behaviour}

No post-critic phase!

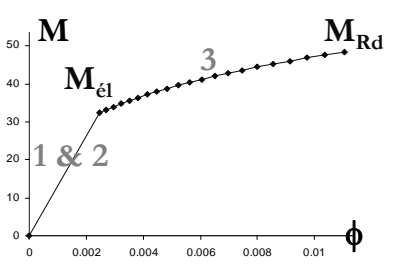

Figure 25. Vertical displacement at the beam extremity (Test F1-6)

In test F1-3, the value of the applied moment $(55.13 \mathrm{kN} . \mathrm{m})$ is lower than the ultimate moment $\mathrm{M}_{\mathrm{u}}$, even after 60 minutes but is equal to the design resistant moment $M_{R d}$ after 54 minutes. At the end of the test, the values of the design resisting moment and the ultimate moment are respectively equal to $50.55 \mathrm{kN} . \mathrm{m}$ and $62.78 \mathrm{kN} . \mathrm{m}$ (see Fig. 26).

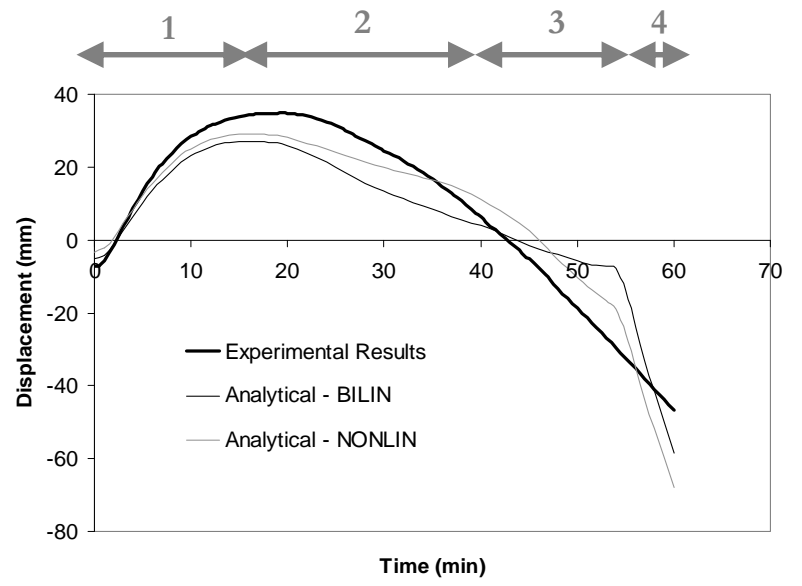

1 : Thermal effect only

2 : Elastic behaviour

3 : Non-linear behaviour

4 : Post-crit. behaviour

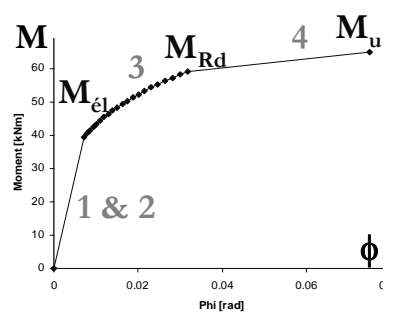

Figure 26. Vertical displacement at the beam extremity (Test F1-3) 
The differences between the experimental and analytical results are due to the fact that the temperatures obtained numerically differ from the real temperatures and to the use of the component method which is a simplified model of reality. Nevertheless, the prediction of the mechanical behaviour of the joint in the fire situation is reasonably good.

The difference between the two tests is due to the difference of temperature in the "protected" bolt rows encased in the slab and in the reinforcement mesh of the slab, as shown in Fig. 27.

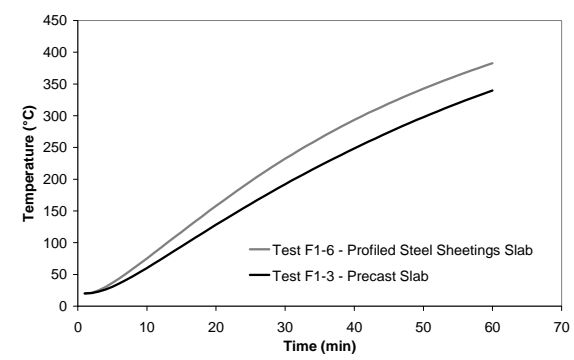

Figure 27. Evolution of temperature in the upper bolt row situated in the slab

\section{Conclusions}

The present article describes recent investigations conducted at the University of Liege on the behaviour of single-sided steel-concrete composite joints at room and at elevated temperatures.

In particular, at room temperature, a new failure mode, not yet covered by the actual codes and standards, has been experimentally identified and an analytical formulation has been developed and validated to predict the appearance of this collapse mode.

The thermal and mechanical behaviours of the joint have also been studied under ISO fire. A procedure has been proposed to evaluate the distribution of temperature in the joint under such a fire, including the part of the beamto-column connection embedded in concrete. The mechanical behaviour of the joint has been obtained by the use of the "hot component method", adapted to account for the reduction of strength and stiffness induced by the elevation of temperature. These calculations have underlined the differences between the distribution of stresses at room temperature and at high temperatures. The influence of the static loading applied previously to the fire test (to simulate damages closed to the ones observed under moderate seismic loading) was limited as the analytical results show a good agreement with the experimental measurements although the action of the earthquake have not been considered in the analytical calculations.. As observed during the tests, this type of joint is sufficiently ductile to avoid any fragile degradation under a limited earthquake. 


\section{Acknowledgements}

The work presented here has been carried out with a financial grant from the Research Fund for Coal and Steel (RFCS) of the European Community. The authors gratefully acknowledge the financial support and appreciate the intensive cooperation among the project partners.

\section{References}

D. Bitar, Y. Ryan, S. Caramelli, W. Salvatore, F. Taucer, J.P. Jaspart, J.F. Demonceau, M. Haller, J. Grijalvo, F.J. Heise, R. Kindmann, M. Kraus, B. Hoffmeister, M. Oppe and H. Stangenberg. Applicability of composite structures to sway frames. Final report, Report EUR 212913 EN, Science Research Development, European Commission, 2006.

O.S. Bursi, F. Ferrario, M. Haller, T. Lennon, L. Bianco, R. Mallardo, J.F. Demonceau, J.M. Franssen, J.P. Jaspart, F. Hanus, E. Bayo, J. Garcia, E. Alderighi, A. Braconi and W. Salvatore. «Prefabricated composite beam-to-concrete filled tube or partially reinforced-concrete-encased column connections for severe seismic and fire loadings », Final report, Science Research Development, European Commission, 2008 (Report accepted - to be published).

J.F. Demonceau \& J.P. Jaspart. Presentation and analysis of tests on single-sided steel and composite joint configurations performed at Liège University. Internal report for the ECSC project 7210-PR-250 “Applicability of composite structures to sway frames”, Liège University, August 2003.

C. Doneux. Study of transfer mechanisms of bending moments at beam-to-column joints in composite structures loaded by a seismic action. PhD thesis, Liège University, 2002 (in French).

EN 1993-1-2 : 2005. Eurocode 3 : Design of steel structures. Part 1-2: General Rules. Structural fire design. European committee for standardization, 2005.

EN 1993-1-8, 2005. Eurocode 3: Design of steel structures - Part 1-8: Design of joints. European committee for standardization, May 2005.

EN 1994-1-1. Eurocode 4: Design of composite steel and concrete structures - Part 1-1: General rules and rules for buildings. European committee for standardization, December 2004.

F. Ferrario. Analysis and modelling of the seismic behaviour of high ductility steel-concrete composite structures. PhD thesis, Trento University, February 2004.

J.-M. Franssen : "SAFIR A thermal/structural program modelling structures under fire”, Engineering Journal, AISC 2005, pp 143-158. 
J.P. Jaspart. Study of the semi-rigidity of beam-to-column joints and its influence on the resistance and stability of steel buildings. PhD thesis, Liège University, 1991 (in French).

T. Lennon \& al. The fire performance of composite connections subject to earthquake damage. $14^{\text {th }}$ World Conference on Earthquake Engineering. Beijing, China, October 12-17 2008.

L. Simões da Silva, A. Santiago, P. Vila Real : “A component model for the behaviour steel joints at elevated temperatures”, Journal of Constructional Steel Research 57 (2001), pp 1169-1195.

Trento University. Partially reinforced-concrete-encased column joints for severe seismic loadings: tests and main results. Internal report for the RFCS project RFS-CR-03034 "Prefabricated composite beam-to-column filled tube or partially reinforced-concrete-encased column connections for severe seismic and fire loadings”, March 2006.

Contact person for the article:

\section{Demonceau Jean-François}

Assistant

Liège University, ArGEnCo Department

$\mathrm{MS}^{2} \mathrm{~F}$ Division

Chemin des Chevreuils, 1 B52/3

4000 Liège

Belgium

Tél: +32-(0)4-3669358

Fax: +32-(0)4-3669192

e-mail: jfdemonceau@ulg.ac.be 